\title{
INTERRELATION OF PERSONALITY CHARACTERISTICS AND THE SUBJECT OF ACTIVITY IN THE PROCESS OF SELF-ORGANIZATION OF PERSONALITY
}

\author{
Marina Pakhmutova ${ }^{1 \star}$, Svetlana Bakhtina ${ }^{2}$, Andrey Rybakov ${ }^{3}$ \\ ${ }^{1}$ PhD student, Mari State University, RUSSIA, quora2011@yandex.ru \\ ${ }^{2}$ Associate professor, Mari State University, RUSSIA, basvet56@mail.ru \\ ${ }^{3}$ Associate professor, Mari State University, RUSSIA, andrrrryb@rambler.ru \\ ${ }^{*}$ Corresponding author
}

\begin{abstract}
In this article, the problem of self-organization of the individual is analyzed. At present, self-organization of the individual is considered in many areas of psychological science (A. Ishkov, V. Klochko, O. Motkov). The existence of various approaches to understanding the self-organization of the individual contributed to the emergence of numerous definitions, often not related. Sometimes the self-organization of the personality is interpreted through the prism of similar concepts: "self-development" (E. Uvarov), "self-government" (M. Peisakhov), "self-regulation" (O. Konopkin). However, only the concept of "self-organization of the individual" makes it possible to understand the essence of the intrapersonal processes that underlies the formation of such key structures as motives, goals, ideals (S. Djakov).

The article substantiates the reference to the concept of "self-organization of the individual". In Russian psychology, the concept of "personality" is closely related to the notion of "activity" (A. Leontiev, B. Ananiev). Personality manifests itself as a subject of activity, as it is included in social relations and labor activity. The differentiation of characteristics related to the personality or to the subject of activity still raises questions among researchers, since the same characteristics can be attributed to both: to the individual and to the subject of activity.

The aim of the work was to study the self-organization of the personality as a process of self-change, taking into account two aspects: personality and activity. Self-organization of activity describes the features of the subject's own activity and includes several stages from goal- setting to the change of activity with a negative result. The personal aspect of self-organization considers the structure of links between individual characteristics and values -semantic units of personality. The resulting integral properties allow the individual to build his behavior in accordance with the assimilated ideals and design his further development.

The article considers the possibility of considering the problem of self-organization from two perspectives. The first position is connected with the manifestation of personality as a subject of activity and is based on the systematic and organized nature of the activity that is performed. The second has its own personal aspect and analyzes the structure of the connections between motives and personal qualities. The combination of these two positions in an empirical study leads to an understanding of the individuality of a person.
\end{abstract}

Keywords: personality, subject of activity, self-organization. 


\section{INTRODUCTION}

In recent years, issues related to the self-organization of man, occupy a central place in all areas of science. The interest of psychologists to this problem has existed for a long time, and its relevance remains today The main issue is the establishment of factors and predictors that can influence the self-organization of a person: physiological characteristics, social environment, the characteristics of work activity (Pakhmutova, 2015, pp. 76-85). Despite some achievements in this field, people often point to insufficient level of self-organization as the cause of lack of time, low performance, deprivation of self-development and self-realization.

In modern Russian psychology the problem of self-organization of a person is connected with the issues of self-development, self-knowledge, self-actualization. In this connection, the ideas of Soviet psychologists concerning cultural predictors of personal growth, the zone of proximal development and the results of interiorization of social experience become topical (Khinkanina, Khinkanin and Pakhmutova, 2014, pp. 311318). Self-organization of the person is interconnected with development of individual qualities which render both positive and negative influence on self-development of the person.

Outwardly, the observed activity of the self-organization of the individual is usually considered to be the success of the subject's activity. The main indicators of organized activities are: goal setting, analysis of conditions of activity, ability to plan, self-control, correction of activities, and volitional qualities. These characteristics in the Russian tradition refer to the concept of "subject of activity" (Ananiev, 2010, p. 267). Using the characteristics of the subject of activity in an empirical study of human self-organization is as necessary, as the analysis of personal characteristics is.

Thus, self-organization as a personal phenomenon is the integration of various personal qualities, the harmonization of personal relations and the expectations of society and self-development. The conditions for self-organization of a person are both an externally organized environment and the structure of a person's qualities.

\section{LITERATURE REVIEW}

\subsection{The phenomenon of self-organization: a systematic approach}

The term "self-organization" came into psychology from the natural sciences, along with the terminology of the system approach. In the twentieth century, the methodology of the system approach was actively included in the toolkit of social research Although these theories have opened many opportunities for psychological research of the person, but the study of intrapersonal processes turned out to be methodologically difficult and required special methods of analysis.

In the 60-70 years of the last century soviet scientists studied profoundly the psychology of self-organization of the person. The result of these investigations was the modeling of a complex of personal qualities that were noted in the group of disciplined students and were absent in the group of underperforming students (Vyatkin, 1999, p. 120). At the same time, the features of the activity itself were not considered as the reasons for the formation of a set of personal characteristics of students, which introduced the probability of error in determining the factors and conditions for self-organization of the individual.

\subsection{Self-organization as a process of intrapersonal integration}

The personality structure has several levels of organization: psychodynamic, social, value-semantic, level of experience, knowledge and skills. Specificity of the interrelations between these levels is manifested in the characteristics of personality behavior. The appearance of factors, hindering the formation of these links, leads to disorganization of the behavior of the individual. And on the contrary, the psychologically correct organization of the conditions of activity contributes to the effective formation of personal substructures, as well as the development of the ability to self-knowledge (Andreeva, 2005, p. 5). The process of formation of connections between various personal substructures is a process of personal self-organization (Bordovskaya, Rozum, 2013, p. 143).

In a generalized form, self-organization of a person is manifested as the ability to "self-grow" its internal resources, as the formation of self-confidence, as a full-fledged realization of its human essence. Selforganization presupposes the formation of worldviews that affect the individual characteristics of a person, in particular, the specificity of perception, understanding and explanation of phenomena by the subject (Golovanova, 2015, pp. 57-61).

Thus, the self-organization of the individual is a process of integrating the acquired ideas about behavior, goals, motivations and self-qualities into a single structure of personality formation. The result of this process is the organization of the person's ideas about himself and the world around him, the consistency of the 
individual "I" images and the desired behavior on the basis of a specific goal. In addition to the formation of intrapersonal links, self-organization of a person is manifested in the organization of human activities. The ability to determine the purpose of the activity, to find ways to achieve it, to plan and control its actions are the most important indicators of personal self-organization.

\subsection{Self-organization of personal activities: a practical aspect}

The success of the performance of the activity and the characteristics of its organization constitute the external aspect of self-organization of the individual. The specific of the organization of the personality structure affects the nature of the subject's activities. The main problem of studying the activities of the subject is the question of indicators of the organization of activities.

The closest to the concept of self-organization of activity are the concepts of self-regulation of mental activity and personal self-government. Self-regulation is a systemically organized process of internal mental activity of a person by initiating, building, maintaining and managing various types and forms of voluntary activity that directly realizes the achievement of the goals. Self-management involves the setting of goals by the subject of activity and communication, with the anticipation of long-term results. Many of these components were included in the holographic model of self-organization of A.D. Ishkov (goal setting, situation analysis, planning, self-control, correction and volitional efforts) (Miloradova, 2005, p. 294). Internal conditions of selforganization are the personal qualities of the subject of the activity (goals, meanings, system of motives, values). The psychological conditions of activity are the external conditions, that contribute to the improvement and self-development of professional competencies, to the development of professional competencies (Bakhtina, Chemekova, 2012, pp. 306-310), as well as cultural forms of transmission of social experience, specific to multi-ethnic regions (Rybakov, 2013, pp. 153-156).

Thus, the main problem of our study became the understanding of the relationship between the personality qualities of the subject and the organization of his activities. Students of Povolzhsky State Technological University (57 people) with a high level of self-organization of activity were selected as respondents. The study of their personal qualities and features of the organization of their activities made it possible to describe the self-organization of the personality as an intrapersonal process of integration.

\section{MATERIALS AND METHODS}

The aim of the study was to establish the relationships between the personal and subject characteristics of the respondents in the process of self-organization of the individual. The research hypothesis consisted in the assumption of the idea that self-organization of the personality unfolds on different structural levels (personal and activity) and manifests itself in the form of integral links between them. The object of the study became the self-organization of students' personality, and the subject - the relationship between personal and subject characteristics. The goal set included the following tasks:

1) Description of the personal profile of respondents with a high level of self-organization;

2) Identify the links between the characteristics of respondents' activities and personal qualities.

Characteristics of the organization of activities were determined with the help of the questionnaire "Questionnaire" Diagnostics of the features of self-organization-39 " developed by A.D. Ishkov on the basis of a holographic model of self-organization (Miloradova, 2005). The results of the questionnaire provide us with the information on the development of the following characteristics of activity: goal setting, situation analysis, planning, self-control, correction and volitional efforts. To identify personal characteristics, the fivefactor personality questionnaire method R. McCray, P. Costa «Five factor model (FFM)» was chosen, which allows assessing the severity of five factors of behavioral traits: openness to experience, extraversion, neuroticism, conscientiousness, cooperation (Khromov, 2000).

\section{RESULTS AND DISCUSSIONS}

Students of the Volga State University of Technology (57 people) participated in the research with a high level of organization of activity. The average age of the subjects is $20,3( \pm 2,1)$ years. The distribution of subjects by sex and profile is presented in Table 1. Statistical analysis was used as a method of statistical analysis, as well as correlation analysis ( $r$-Spearman coefficient). Statistical data package Statistica 6 was used for data processing. 
Table 1. Distribution of subjects by sex and profile of training.

\begin{tabular}{|c|c|c|c|c|}
\hline \multicolumn{2}{|c|}{} & \multicolumn{2}{|c|}{ Profile of specialty } & \multirow{2}{*}{ N } \\
\cline { 3 - 4 } \multicolumn{2}{|c|}{} & Technical (people) & Humanitarian (people) & \\
\hline \multirow{2}{*}{ sex } & men & 22 & 7 & 29 \\
\cline { 2 - 4 } & women & 9 & 19 & 28 \\
\hline \multicolumn{2}{|l|}{ Total, people } & 31 & 26 & 57 \\
\hline
\end{tabular}

The determination of average indicators for all scales of the methods that were used showed that students with a high level of self-organization are characterized by certain characteristics related to personal qualities and activities (Table 2).

Table 2. Average indicators on the scales of the methods "Questionnaire" Diagnosis of the features of selforganization-39 "' and "Five-Factor Personal Questionnaire" ( $\mathrm{N}=57)$.

\begin{tabular}{|c|c|c|c|c|}
\hline Scale name & Mean & Min & Max & Std.Dev. \\
\hline Purpose & 7.60 & 5.00 & 10.00 & 1.12 \\
\hline Situation Analysis & 7.53 & 4.00 & 10.00 & 1.52 \\
\hline Planning & 7.40 & 5.00 & 10.00 & 1.40 \\
\hline Self-monitoring & 7.40 & 4.00 & 10.00 & 1.50 \\
\hline Correction & 7.40 & 1.00 & 10.00 & 2.47 \\
\hline Willpower & 7.47 & 5.00 & 10.00 & 1.35 \\
\hline Total level of self-organization & 7.46 & 7.00 & 10.00 & 0.78 \\
\hline Extroversion & 54.32 & 33.00 & 68.00 & 8.02 \\
\hline Cooperation & 52.82 & 27.00 & 74.00 & 9.28 \\
\hline Good Faith & 57.77 & 35.00 & 73.00 & 8.08 \\
\hline Neuroticism & 47.87 & 26.00 & 71.00 & 10.17 \\
\hline Openness to experience & 57.11 & 43.00 & 70.00 & 7.21 \\
\hline
\end{tabular}

The results presented in the table show that students with a high level of self-organization are characterized by high scores on the scale "Good Faith", "Openness to Experience", "Extraversion". Virtually all characteristics of self-organization of activities are at the same level of development, which determines the high overall level of organization of activities.

Interrelations between the characteristics of students' activities and personal qualities were established using correlation analysis. As a result, the strongest links were found between goal-setting and two groups of behavioral traits: extraversion $(-0.40,0.001<p<0.01)$ and integrity $(0.40,0.001<p<0.01)$. This fact can be considered as the probability of the influence of these qualities of personality on the self-organization of activities. Moreover, extraversion and conscientiousness have opposite signs of correlations, it is meant that this influence is of a differently directed character. At the same time, extraversion negatively correlates with 
the analysis of the situation $(-0.33,0.01<\mathrm{p}<0.05)$, planning $(-0.23,0.05<\mathrm{p}<0.09)$, self-control $(-0.25,0.05$ $<\mathrm{p}<0.09)$ and positively with correction $(0.40,0.001<\mathrm{p}<0.01)$. In contrast, good faith positively influences the analysis of the situation $(0.30,0.01<p<0.05)$, planning $(0.34,0.01<p<0.05)$ and self-control $(0.23,0,05$ $<\mathrm{p}<0.09$ ).

The openness to the experiment is negatively correlated with the analysis of the situation $(-0.24,0.05<\mathrm{p}$ $<0.09)$ and positively with correction $(0.30,0.01<p<0.05)$. Cooperation does not have a significant impact on the self-organization of activities. Correction of activity depends on different personal qualities, while good faith $(-0.30,0.01<\mathrm{p}<0.05)$ and neuroticism $(-0.26,0.01<\mathrm{p}<0.05)$ are affected negatively.

\section{CONCLUSION}

On the basis of the conducted research it can be concluded that the self-organization of the personality is manifested in the form of well-organized activity, which is based on the ability to target, analyze the conditions of activity, planning, self-control and adjustment of activities. The main personal qualities that contribute to the self-organization of activities are conscientiousness and low extraversion. Correction of activities as the most difficult stage of activity is compensatory (it is realized in case of a negative result) and depends on different personal qualities: extraversion, conscientiousness, neuroticism, openness to experience.

Cooperation as a personal property does not affect the organization of activities, that is respondents with different levels of attitudes towards others can successfully organize their activities. The volitional qualities shown in the activity are not related to personal traits as well, because they represent a separate mental entity.

Thus, the study of self-organization of the personality in two aspects (personal and activity) made it possible to identify the psychological factors of the organization of activity. Firstly - the factor of development of certain personal qualities. Secondly, self-organization is affected by the specific nature of the links between the characteristics of the individual and the subject of activity. In addition to these factors, the psychologically correct organization of the conditions of activity will also contribute to the self-development of the individual, the formation of his readiness for self-organization (Lezhnina, 2009, pp. 21-25).

It is likely that the complication of theoretical models of self-organization of the personality (inclusion of a large number of variables in them) will open the possibility for more effective correction of failure of the subject in various activities. Perspective is the study of the role of motivation and values in the activation of the process of self-organization of the individual.

\section{REFERENCE LIST}

Ananiev, B. G. (2010). Man as an object of knowledge. St. Petersburg.

Andreeva, S. N. (2005). Dynamics of personal substructures as indices of psychological readiness of future teachers for pedagogical activity. The dissertation author's abstract on competition of a scientific degree of the candidate of psychological sciences / Kazan State Technical University. A.N. Tupolev. Yoshkar-Ola.

Bakhtina, S. V., Chemekova, N. R. (2012). Development of strategic thinking: pedagogical ideas of history and modernity (on the example of cross-technologies and pedagogical ideas of A. S. Makarenko and V. A. Sukhomlinsky). The world of science, culture, education, vol.6 (37).

Bordovskaya N. V., Rozum S. I. (2013). Psychology and pedagogy. SPb: Piter.

Golovanova, T. N. (2015). Psycho-pedagogical conditions of formation of a holistic understanding and explanation through religious and nonreligious attitude to the world. Bulletin of the Mari State University, vol. 4(19).

Khinkanina, A. L., Khinkanin, A. P., Pakhmutova M. A. (2014). Present-day meaning of personal development notion in terms of cultural-historical theory of L. S. Vygotsky (based on the survey of building design major students). Psychology and psychiatry, sociology and healthcare, education. DOI: 10.5593/sgemsocial2014/B11/S1.041.

Khromov, A. B. (2000). Five-factor personality questionnaire: Study guide. Kurgan: Publishing House of the Kurgan State. University. 
Lezhnina, L. V. (2009). Individual Education Plan as Innovation in Vocational Training of Educational Psychologists. Standards and monitoring in education, vol. 2.

Miloradova, N. G. (2005). Psychology and pedagogy. Moscow: Gardariki.

Pakhmutova, M. A. (2015). Personalities self-organization features of students included in the research activities at different stages of training. Actual problems of psychological knowledge, vol. 1.

Rybakov, A. V. (2013). Students' patriotic education based on cultural traditions of peoples living in multiethnic region. Bulletin of the Chuvash State Pedagogical University im. I. Ya. Yakovlev, vol. 1-2 (77).

Vyatkin, B. A. (1999). The style of self-organization. Integral individuality of a person and its development. Moscow: Publishing house of Moscow psychological-social Institute; Voronezh: Publishing house NPO "MODEK". 